\title{
LOS PERSEGUIDORES DE CORTÁZAR Y WILENSKI: TEMPORALIDAD Y VIAJE EN LA NARRACIÓN ESCRITA Y AUDIOVISUAL
}

\author{
Laura Ros Cases \\ Universidad de Murcia \\ laura.ros1@um.es
}

Resumen: El presente trabajo estudia el tratamiento de la temporalidad en la novela corta $E l$ perseguidor, de Julio Cortázar (1957), y la película homónima de Osías Wilenski (1962). En ambas piezas, el viaje en el metro constituye un punto de inflexión en la búsqueda de Johnny: gracias a la capacidad de extrañamiento que presenta el subterráneo, las coordenadas espaciotemporales adquieren un carácter fluctuante. En la narración de Cortázar, la fragmentación discursiva de los hechos remite a la propia obsesión del saxofonista por la temporalidad. En la cinta de Wilenski, el recurso al montaje de correspondencias revela un tratamiento formal acorde a la simultaneidad que persigue Johnny.

Palabras clave: Julio Cortázar, Osías Wilenski, El perseguidor, cine argentino, literatura comparada.

\section{CORTÁZAR AND WILENSKI'S PURSUERS: TEMPORALITY AND JOURNEY IN WRITTEN AND AUDIOVISUAL NARRATIVE}

\begin{abstract}
The present paper studies the treatment of temporality in Julio Cortázar's 1957 nouvelle The Pursuer, and Osías Wilenski's 1962 homonymous film. In both works, travelling stands as a turning point in Johnny's quest: through the sense of strangement provided by the subway wagon, spatial-temporal coordinates acquire a fluctuant quality. In Cortázar's narrative, the use of discursive fragmentation concerning the facts points directly to the saxophonist's own obsession for temporality. In Wilenski's flick, the utilization of the cinematic assembly based on correlations reveals a formal treatment matching Johnny's pursue of simultaneity.
\end{abstract}

Keywords: Julio Cortázar, Osías Wilenski, The Pursuer, Argentinian cinema, comparative literature.

DOI: https://doi.org/10.24029/lejana.2020.13.439

Recibido: el 2 de noviembre de 2018

Aceptado: el 1 de marzo de 2019

Publicado: el 19 de febrero de 2020 


\section{Introducción ${ }^{1}$}

A pesar de que Julio Cortázar ha trascendido por su fama como escritor, es bien conocido su gusto por el resto de artes y la integración que de estas hizo en su actividad literaria. La música, concretamente el jazz, es una de las temáticas recurrentes en su narrativa y ensayos, mientras que su pasión por el cine — recordemos, por ejemplo, sus comentarios a las películas de Buñuel Los olvidados y El ángel exterminador - se vio posteriormente reflejada en la adaptación de varios de sus cuentos: la trilogía de Manuel Antín (1962-1965), El perseguidor (1962) de Osías Wilenski, Blow-Up (1966) de Michelangelo Antonioni, Week-end (1967) de Jean-Luc Godard o Diario para un cuento (1998) de Jana Bokova, entre otras.

Dentro del extenso corpus de adaptaciones de las historias del escritor, el filme de Wilenski quizás sea uno de los menos tratados por la crítica; por esta razón, así como por su afinidad con la relevante Generación del 60, la hemos elegido como objeto de nuestro estudio. Tanto en la novela corta como en la película homónima asistimos a la desaforada búsqueda de Johnny. Concretamente, dedicaremos nuestro análisis a un pasaje determinado: el viaje que el saxofonista realiza en el metro, donde los límites del espacio y el tiempo desafían al ordenamiento cronológico. La dilatada temporalidad subjetiva en la percepción del protagonista, que contrasta con el breve lapso objetivo del desplazamiento, supone para el mismo la comprensión de las posibilidades que entraña el otro lado de la realidad y, posteriormente, su frustración por no poder alcanzarlas de forma consciente. Asimismo, señalaremos la relación que esto presenta con el resto del entramado de la novela corta y los recursos empleados por Wilenski para la traslación formal de este pasaje al medio audiovisual.

\section{La génesis de los perseguidores y su relación con la Generación del 60}

Aunque El perseguidor se publica por primera vez en la Revista Mexicana de Literatura, en los números 9-10 en 1957, posteriormente se incluyó en el volumen Las armas secretas (Buenos Aires, Sudamericana, agosto de 1959) junto con los cuentos "Cartas de mamá", "Los buenos servicios", "Las babas del diablo" y "Las armas secretas" (Aquilanti y Barea, 2014: 48). En una carta de 1955 escrita a Jean Barnabé, Cortázar resume algunos aspectos clave para la comprensión de esta obra: "su tema es aparentemente sencillo: la vida - y sobre todo la muerte - de un músico de jazz. [...]. Quiero presentarlo como un caso extremo de búsqueda, sin que se sepa exactamente en qué consiste esa búsqueda, pues el primero en no saberlo es él mismo" (2000a: 328). En efecto, El perseguidor se centra en la vida del saxofonista Johnny Carter: un artista genial y desmesurado cuyos excesos con el alcohol y las drogas acentúan su carácter errático. Toda su experiencia vital es narrada por Bruno, un analítico estudioso de jazz que está escribiendo su biografía. A través de ese tamiz perceptivo del narrador en primera persona conocemos el presente de Johnny en París, donde vive con su novia Dédée en un desamparado cuarto de hotel. Del mismo modo, también asistimos a escenas de su pasado en Baltimore y Nueva York: su adolescencia; su relación con otra mujer, Lan, y con su hija Bee; las estancias en centros psiquiátricos; la amistad con la marquesa Tica,

\footnotetext{
${ }^{1}$ Esta investigación ha sido financiada por el Ministerio de Educación, Cultura y Deporte a través de una ayuda predoctoral para la formación del profesorado universitario (FPU16/07424).
} 
etc. Las diferentes sesiones de grabación y su trayectoria musical se ven afectadas por la inconsistencia del carácter de Johnny: su obsesión por la apreciación temporal y la imagen de los campos llenos de urnas le acosan constantemente. La muerte repentina de su hija no hace sino empeorar su estado y le afirma en su decisión de regresar a Nueva York, donde morirá tras pronunciar unos versos de su querido Dylan Thomas: "Oh, hazme una máscara" $(280){ }^{2}$

La obra muestra la voluntad del escritor por plasmar el mundo del jazz, del que era un reconocido admirador. Cortázar señala de manera explícita su intención de "inventar una «biografía» ficticia" en torno a la figura de Charlie Parker, ${ }^{3}$ de cuya muerte ha tenido noticia recientemente (2000a: 328), y así lo cumple con el epígrafe que abre el texto - "In memoriam Ch. P." (235)—. Además, como muy bien ha apuntado Mario Goloboff, en el nombre del protagonista también se esconden las alusiones a otros dos grandes músicos de jazz: Johnny Hodges y Benny Carter (1998: 112). La crítica ha sido unánime en destacar El perseguidor como un punto de inflexión en la trayectoria literaria cortazariana. Este cambio de rumbo respecto al resto de sus publicaciones presenta una doble vertiente. Por un lado, el escritor desplaza el elemento temático que había motivado gran parte de sus composiciones anteriores:

Hasta ese momento me sentía satisfecho con invenciones de tipo fantástico. [...] sino cuando escribí El perseguidor había llegado un momento en el que sentí que debía ocuparme de algo que estaba mucho más cerca de mí mismo. En ese cuento dejé de sentirme seguro. Abordé un problema de tipo existencial, de tipo humano [...]. En El perseguidor quise renunciar a toda invención y ponerme dentro de mi propio terreno personal, es decir, mirarme un poco a mí mismo. Y mirarme a mí mismo era mirar al hombre, mirar también a mi prójimo. (Harss, 1966: 273-274)

Por otro lado, la complejidad que supone el acercamiento a esa temática diferente de su producción requiere de un nuevo planteamiento. Según señala Raquel Arias, "lo que Cortázar necesita narrar en ese cuento le aleja de los parámetros establecidos por él mismo para el género cuento, donde la intensidad y la brevedad son lo primero" (2014: 99).

No podemos adentrarnos en el análisis de las obras sin antes presentar al autor de la segunda de ellas. Mientras que la figura del escritor es ampliamente conocida a nivel internacional, como también lo son otros directores de cine que han llevado sus obras a la gran pantalla - Manuel Antín, Michelangelo Antonioni o Jean-Luc Godard-, Osías Wilenski es uno de los grandes desplazados en el estudio de las adaptaciones cinematográficas de la narrativa cortazariana. Por ello, nos parece necesario dedicar una reflexión más extensa sobre su biografía y el contexto en el que se inserta. Nacido el 2 de diciembre de 1933, este argentino comenzó su carrera artística en el campo de la música. Fue becado para estudiar en la Juilliard School of Music de Nueva York en 1949; allí estableció contacto con los cineclubes de la zona y sus gustos se desplazaron hacia lo cinematográfico. A su regreso de Estados Unidos realizó su primera incursión en el mundo fílmico y compuso la banda sonora de la primera versión de El negoción, dirigida por Simón Feldman (1956). Realizó asimismo una serie de cortometrajes, cuyos negativos fueron quemados por el propio

\footnotetext{
${ }^{2}$ De aquí en adelante, en las citas donde únicamente aparece el número de página se hará referencia a la edición de 2015 de El perseguidor de Julio Cortázar, véase en la bibliografía. (N. del E.)

${ }^{3}$ Para un cotejo detallado de las similitudes entre el personaje real y Johnny Carter, recomendamos acudir al artículo de Rodolfo Borello "Charlie Parker: «El Perseguidor»" (1980), cuya referencia completa incluimos en la bibliografia.
} 
autor en 1966 (Anchou, 2005: 199). Únicamente salvó dos de ellos: Moto perpetuo (1955) y Ramón Gómez de la Serna (1964) (Martínez, 2004: 213). A su primer largometraje como director, El perseguidor (1962), le siguieron dos cintas: Pate Katelin en Buenos Aires (19681969) y Dale nomás (1974). En el primero de ellos realizó una codirección junto a Juan Carlos Thorry y Bruce Bilson; sin embargo, debido a diversos problemas de producción, este filme nunca llegó a ser estrenado. La segunda película, ya con dirección íntegra de Wilenski, unifica en su guion varios relatos de Héctor Lastra, Mario Benedetti, Rodolfo Walsh y Pedro Orgambide (Manrupe y Portela, 2001: 153, 450). Tras sufrir la subasta pública de los negativos de El perseguidor, Wilenski decidió retomar su carrera musical y establecerse en España (Anchou, 2005: 200).

Por su cronología y las características de su obra, la crítica cinematográfica argentina ha relacionado la obra de Wilenski con el panorama renovador de la Generación del 60. Si bien no forma parte de los nombres principales de esta corriente regeneradora — pues, como hemos visto, su incursión en el cine no fue muy duradera-, los manuales dedicados al estudio de esta generación sí le incluyen como uno de esos jóvenes realizadores que pretendían renovar el medio cinematográfico y su lenguaje narrativo (Martín, 2003; Aguilar, 2005). Concretamente, señalan la cinta El perseguidor como su única contribución a esta corriente (Luka, 2003: 285). Es por esto que se hace necesario introducir algunas de las características esenciales de esta tendencia fílmica, con el objetivo de entender las peculiaridades del cine de Wilenski en su momento.

Según Paula Félix-Didier, el contexto de gestación de este nuevo grupo se caracterizó por la inestabilidad político-económica de la época posperonista y por una modernización cultural; los cambios en estos aspectos influyeron en la transformación decisiva del panorama cinematográfico argentino. Todos estos cambios sociales se vieron concretizados, por ejemplo, en la creación de la conocida como "Ley de cine". El decreto-ley 62/57 estimuló la producción independiente de una manera decisiva, pues reconocía tanto el carácter industrial del cine como su valor artístico (y, con ello, su función como vehículo de cultura nacional). A Leopoldo Torre Nilsson y Fernando Ayala, figuras predecesoras de esta Generación del 60, le siguió un grupo heterogéneo de jóvenes realizadores formados en el ámbito de los cineclubes y talleres vocacionales, los cuales ejercieron una fundamental tarea como centros alternativos de circulación de ideas y de aprendizaje mediante la cinefilia. Sus primeras incursiones, como ocurrió en el caso de Wilenski, comenzaron en el terreno del filme corto y se prolongaron al largometraje (Félix-Didier, 2003: 11-20). Simón Feldman señala que, si ya entre 1959 y 1961 irrumpieron los primeros representantes de la nueva generación, los años 1962-1965 constituyeron el apogeo de esta manifestación cinematográfica. En ese primer año cumbre se presentan películas muy señaladas: Dar la cara de José Martínez Suárez, El hombre de la esquina rosada de René Mugiga, La cifra impar de Manuel Antín, Los inundados de Fernando Birri o Los jóvenes viejos de Rodolfo Kuhn. A excepción de esta última, todas las cintas mencionadas tenían una base literaria — los libros de David Viñas, Jorge Luis Borges, Julio Cortázar y Mateo Booz, respectivamente- (Feldman, 1990: 61-66). Y es que, como apunta el crítico de cine José Agustín Mahieu, una de las principales aportaciones de este nuevo cambio cultural fue la elección de fuentes literarias contemporáneas y nacionales (1980: 641); Wilenski hará lo propio mediante la selección de El perseguidor y el conjunto de relatos que constituyeron el guion de su tercera película. 
Asimismo, el grupo de esta década se caracterizó, como muchas otras tendencias europeas de los mismos años, por la confrontación con el cine anterior y la expresión personal que cultivaron sus directores. Las principales aportaciones de esta nueva corriente fueron el uso renovador del lenguaje cinematográfico y el cambio de los temas y los modos narrativos. Respecto a estos últimos, por ejemplo, se introdujo la presencia de la ciudad como espacio y como tema. En lo que toca a las aproximaciones formales, el nuevo cine relegó a un segundo plano el montaje clásico, lineal o tradicional y se preocupó por explorar las posibilidades expresivas de otras estructuras narrativas que permitieran ahondar en el mundo interior de los personajes y en la forma de representar esa subjetividad (Félix-Didier, 2003: 11-20).

Sin duda, lo más conseguido de la cinta es la ruptura de esta para con el lenguaje tradicional del medio - y la razón por la que la hemos incluido en nuestro estudio-. Esa importancia de la plasmación de la psicología de los personajes probablemente fue lo que llamó la atención de Osías Wilenski a la hora de adaptar la nouvelle de Julio Cortázar. Según apuntan Manrupe y Portela, Ulyses Petit de Murat fue el guionista encargado de adaptar El perseguidor para su traslación fílmica. Aunque la producción está fechada en 1962, el filme fue secuestrado por un juez de menores de edad a causa del desnudo de la actriz Zulma Faiad - que interpreta a Baby Lennox - en una de las escenas, que había filmado siendo menor. Por esto, la película no se estrenó hasta el 10 de marzo de 1965 (Manrupe y Portela, 2001: 460). El propio Cortázar tuvo la ocasión de verla en el Festival de Cine de Sestri Levante de 1963, al que había acudido para trabajar en el guion de Circe (1964) junto a Manuel Antín. La película, sin embargo, no le causó muy buena impresión (Cortázar, 2000a: 600), aunque sí elogió la banda sonora, compuesta e interpretada por los saxofonistas Rubén y Leandro "Gato" Barbieri (Cortázar, 2000b: 862). Su visionado de la película, como él mismo admitió, se vio condicionado por las cuestiones económicas en torno a la producción de la misma. La revisión de las misivas que se intercambiaba con Antín — quien, por su amistad y por la distancia geográfica, ejerció de intermediario en este tema- nos dan varios ejemplos de los malentendidos entre Cortázar y Wilenski. Señalaremos uno de ellos, fechado en noviembre de 1962:

Me asombra - y me irrita, no te lo oculto- el silencio de ese señor en materia financiera, al punto que lamento ahora haberme dejado ganar por su desesperación telefónica (seis minutos a los gritos) y haberle dado mi consentimiento sin la menor garantía. Comprendé que no pongo en duda sus buenas intenciones, pero tengo en las manos una carta suya en la que me dice que hacia el 10 de noviembre se me pagará lo convenido, y estamos a fin de mes sin haber recibido la menor noticia. (Cortázar, 2000a: 518-519)

Pese a todo, es necesario valorar la película como obra artística. Aunque la cinta sigue la trama argumental de su texto base, introduce variaciones que afectan de manera significativa a su relación con la novela corta. En primer lugar, la ambientación de la historia se traslada a Buenos Aires, ya sea por razones extra-cinematográficas o por la importancia de la integración de la ciudad en los filmes de la Generación del 60. Consecuentemente, en la película desaparece cualquier rasgo afrodescendiente de sus personajes y se adaptan a la nominalización española; así, Johnny Carter pasará a llamarse Juan Ríos —encarnado por Sergio Renán—, aunque se refieren a él de manera intermitente con el apodo estadounidense.

Asimismo, encontramos una ordenación prácticamente lineal de los acontecimientos del relato. Recordemos que, en este, los hechos comienzan a partir de la visita de Bruno a la 
habitación del hotel de París, donde Dédée está cuidando de un Johnny enfermo y que acaba de perder su saxo en el metro. Aunque el filme también presenta un inicio in medias res, nos introduce en un punto anterior de la vida de Juan: su relación con Lan - que aquí recibe el nombre de Marta, interpretada por Anadela Atzón_-, sus comienzos en el mundo del jazz los locales porteños son el correlato del Club 33 al que acude Johnny en Baltimore y Nueva York - y la presencia de Bruno desde el inicio de su carrera - a quien da vida Zelmar Gueñol—. Estos sucesos, que también aparecen descritos en la novela corta mediante las reflexiones analépticas de Bruno, nos dan la oportunidad de asistir a la gradual decepción de Juan con el mundo. En los minutos iniciales de la película asistimos a uno de sus conciertos, en el que lo encontramos visiblemente contento; este feliz estado pronto da paso al tormento interno del protagonista. Mientras camina por las calles de Buenos Aires junto a Marta, quien le está hablando de su intención de formar una familia, él se limita a decir lo siguiente: "La ciudad se está deshaciendo. Está podrida. Ya no queda nada que no esté podrido. [...] Todo se muere" (Wilenski, 1965: 08:35-09:00). Estas sentencias se alternan con la presencia de Juan en los bares en una actitud derrotada — una clara escenificación de la debilidad de Johnny por el alcohol- y sus actos erráticos durante los ensayos.

El último cambio fundamental que nos interesa destacar es el desplazamiento de Bruno como narrador, debido en parte a las exigencias del medio fílmico: a diferencia de la nouvelle, el espectador elabora sus impresiones sobre Juan sin la mediación del monólogo interior del crítico. En el texto, las reflexiones de Bruno sobre Johnny y sus momentos de lucidez son el centro de la historia; la película, por su formato audiovisual, debe relegar la narrativa en la sucesión de acciones. Si bien es cierto que un abuso de la voz en off para adaptar el estatuto del narrador habría podido caer en el exceso, el carácter altamente subjetivo y focalizado del papel desempeñado por Bruno en el texto de Cortázar articula muchos de los elementos del mismo. De esta manera, muchos aspectos de la novela corta se atenúan o directamente se eliminan en la traslación fílmica, como la oposición entre el crítico y el artista o el cínico academicismo de Bruno. Así, en la obra de Wilenski la dualidad no está tan marcada como en el texto cortazariano, sino que más bien asistimos a la historia de Juan. Aunque la búsqueda de este sigue siendo el motor central de la película, la pérdida de la visión externa de Bruno afecta a la profundidad psicológica de la cinta y hace que el protagonista se asemeje más a un pobre diablo atormentado que a un visionario: "pese a sus buenas intenciones, el lenguaje cinematográfico de Wilenski [...] no alcanza a encontrar el equivalente necesario para transmitir la experiencia metafísica, que se resiste a la imagen concreta" (Mahieu, 1980: 643-644).

A estos distanciamientos de los elementos presentes en el texto se une el carácter altamente fragmentario de la película, que Neifert califica de "retorcido simbolismo y de una confusa pretensión de cine moderno [...] hasta extremos de incoherencia" (2003: 367). En efecto, las escenas suelen ser extremadamente breves y en muchas ocasiones el nexo entre ellas es demasiado débil para que el espectador logre su comprensión. Si valorásemos la película únicamente como una adaptación de El perseguidor — algo a todas luces corto de miras-, los escollos hasta ahora presentados podrían considerarse insalvables. Sin embargo, la cinta de Wilenski queda entroncada con esos visos de renovación fílmica que representó la Generación del 60 y, si bien en ocasiones no quedan especialmente logrados, en otras hacen necesario que se rescate a este filme del olvido. Nos referimos, concretamente, al tratamiento 
de la búsqueda y su relación con el manejo formal de la temporalidad. La película del cineasta argentino no solo la plantea de una manera análoga — aplicada, por supuesto, a los recursos audiovisuales - , sino que es uno de los mayores rasgos de modernidad del filme, como tendremos ocasión de argumentar más adelante.

\section{La búsqueda acronológica de Johnny y la escenificación visual de la temporalidad}

Sin duda, uno de los temas principales del relato El perseguidor es el tiempo; más concretamente, la obsesión que Johnny tiene con este concepto. Bruno nos relata esta manía mediante la introducción de una anécdota de manera analéptica. El momento al que se refiere tuvo lugar en una sesión de grabación en 1949 o 1950, mucho antes de que ambos se trasladasen a París:

Y justamente en ese momento, cuando Johnny estaba como perdido en su alegría, de golpe dejó de tocar y soltándole un puñetazo a no sé quién dijo: [...] "Esto ya lo toqué mañana, es horrible, Miles, esto ya lo toqué mañana", y no lo podían hacer salir de eso, y a partir de entonces todo anduvo mal, Johnny tocaba sin ganas y deseando irse (a drogarse otra vez, dijo el técnico de sonido muerto de rabia), y cuando lo vi salir, tambaleándose y con la cara cenicienta, me pregunté si eso iba a durar todavía mucho tiempo. (237-238)

La preocupación de Johnny por la consecución de la simultaneidad va a acosar constantemente al saxofonista. La música le ayuda en su búsqueda, aunque no puede hacer nada por facilitar su comprensión. El protagonista señala que, ya en su adolescencia, estas situaciones le sacaban de ese tiempo cronológico: "yo creo que la música me metía en el tiempo. Pero entonces hay que creer que este tiempo no tiene nada que ver con... bueno, con nosotros, por decirlo así" (239). Con esto, Johnny apunta a la salida de un orden en el que solo existe la concepción tradicional de la temporalidad, a una apertura hacia lo insólito y la percepción de la otra parte de esas coordenadas, en las que el tiempo se convierte en algo subjetivo. De hecho, la música no lo saca del tiempo, sino que, como él mismo matiza, le permite otra manera de percibirlo en su totalidad. Al igual que el jazz, el metro es un "ascensor del tiempo" (240), un lugar en el que Johnny percibe el tiempo de manera elástica, donde se pueden solapar pasado y presente, encontrar a personas de distintos lugares: "viajar en el métro es como estar metido en un reloj. Las estaciones son los minutos, comprendes, es ese tiempo de ustedes, de ahora; pero yo sé que hay otro, y he estado pensando, pensando..." (244).

Con esta búsqueda incesante, la novela corta del escritor argentino se encuadra en lo que Lida Aronne-Amestoy ha calificado como la "isotopía del perseguidor" (1983: 382). Así, Johnny queda emparentado con los personajes de Los premios, Rayuela e, incluso, de algunos cuentos como "La banda" (Filer, 1972: 197). Según se explicita en el texto, en la narración de Cortázar encontramos a dos perseguidores - $-\mathrm{y}$, asimismo, dos maneras de percibir la temporalidad- El primero de ellos es Bruno, cuya tarea autoimpuesta es redactar la biografía de Johnny. Su búsqueda cínica, en algunos momentos deshumanizada, se completa solo en parte, pues nunca llega a comprender la actitud de Johnny. Aunque reina de manera generalizada el descreimiento por parte del crítico, encontramos acercamientos puntuales entre la percepción del protagonista y del narrador: "envidio a Johnny, a ese Johnny del otro lado, sin que nadie sepa qué es exactamente ese otro lado" (249). Bruno se debate entre los 
celos que siente por Johnny —en cuanto a su música y a sus reflexiones-y su preocupación por su carácter autodestructivo. Una preocupación que, en gran parte, proviene de su interés académico y económico como estudioso oficial de Johnny y su música.

Por su parte, la búsqueda del saxofonista adquiere un carácter estético, que incluso se podría relacionar con una experiencia mística. Pero, sobre todo, lo que el saxofonista busca es una manera diferente de percibir la experiencia vital a través de la integración de una nueva temporalidad. Su concepto subjetivo del tiempo entra en conflicto con el resto del mundo representado en la figura de Bruno-, que entiende lo cronológico y lo lineal como única manera de percibir el tiempo. Graciela García apunta al respecto lo siguiente: "what Johnny suggests [...] [is that] our notion of linear time [...] its illusory, and that «real time» only emerges through flashes of transient moments that take us away from our firm belief in linear chronology" (2003: 38). Así, en palabras de Sosnowski, El perseguidor "enfrenta dos visiones de la realidad: la de Johnny Carter, que por ser un hombre instintivo se reduce a intuiciones, a sentimientos ocultos e irreducibles a formulaciones lógicas; y la de Bruno, [...] que se aferra a su fe en la verdad absoluta de un orden establecido por una perspectiva científico-burguesa" (1973: 60). La búsqueda de ese tiempo absoluto y no delimitado encuentra su contrapunto en la constante marca textual de la temporalidad por parte de Bruno. Al comienzo del relato, el saxofonista dirá a su amigo: "Tú no haces más que contar el tiempo [...]. El primero, el tres, el veintiuno. A todo le pones un número, tú" (2015: 236). Sin embargo, parece que Bruno acaba por contagiarse mínimamente de la percepción de Johnny, pues en ocasiones los periodos temporales a los que alude no terminan de encajar con el presente o futuro en el que se desarrolla cada una de las acciones: "Hace un rato que no nos veíamos - le he dicho a Johnny-. Un mes por lo menos" (236). Esa continua lucha a contracorriente con la convención y, sobre todo, con la inefabilidad de dichas revelaciones, hace que Johny se inserte en una búsqueda incomprendida cuyo fin se alcanza una vez y no se repite. La persecución, además, va a quedar frustrada, ya que Johnny no consigue alcanzar conscientemente la simultaneidad espacio-temporal que experimenta de manera ajena a su voluntad; en otras palabras, no consigue pasar al otro lado de la puerta.

Esta doble presencia del perseguidor remite a la polaridad característica de muchas obras de Cortázar. La presencia de mundos divididos y el esfuerzo por integrarlos va a resumirse en la dualidad presente en el lado de acá y el lado de allá. Esos mundos polarizados pueden encarnarse en dos lugares, momentos psicológicos o cronológicos distintos; dicha dicotomía queda patente en la doble cara del perseguidor. Unas veces empíricos miopes, otras alienados clarividentes, ninguno de ellos puede ejercer de manera aislada esa búsqueda integradora; de ahí que el perseguidor sea a menudo la identidad perseguida (AronneAmestoy, 1983: 381-388). Tanto la representación prácticamente unilateral del conflicto de la novela corta por parte de Wilenski como la ausencia de ese intento de comprensión por parte de Bruno impiden que se manifieste la impronta metafísica de una manera orgánica en la cinta. Solo se potencia uno de los perseguidores y, por lo tanto, no se consigue desarrollar completamente a ninguno de ellos ni se entiende del todo la búsqueda de Johnny.

Esta persecución frenética del protagonista se encuentra asimismo con otro escollo: el de la propia comprensión de su búsqueda. Como señala Malva Filer, el problema de Johnny es que se trata de "un hombre dotado de un sentimiento metafísico puramente intuitivo, pero totalmente desprovisto de recursos intelectuales para analizarlo. La música es su único 
instrumento de expresión y, al mismo tiempo, de búsqueda" (1972: 199). Johnny pierde el saxo en el metro; con él, pierde la concepción del tiempo ordinario y el instrumento con el que consigue traspasarla. En realidad, se insiste en la falta de recursos intelectuales de Johnny para su búsqueda, pero el lenguaje mismo es ya un obstáculo. La búsqueda del protagonista será la de una apertura consciente, ajena al lenguaje y, también, a su problemática. Así, László Scholz señala que, en su obra

Cortázar hace hincapié en el hecho de que la lengua es tan solo uno de los medios de la comunicación humana y, con vistas a la mejora de esta, introduce otros canales informativos que [...] llamamos medios audiovisuales. En realidad, se trata de sistemas de comunicación paralelos con el verbal que por su mera existencia afectan a los elementos petrificados de la lengua, a la vez que constituyen soluciones estéticas muy eficaces. (2000: 17)

La desconfianza en el lenguaje como sistema de aprehensión de la realidad total lleva a Johnny a explorar de una manera ilógica e inconsciente una nueva apertura a través de medios de comunicación —o métodos de comprensión — alternativos, como el del jazz. Por su parte, Wilenski trasladará esa búsqueda de Johnny a un nuevo medio: el audiovisual.

Patricia Reagan apunta que, si bien la música es el método de comunicación de Johnny, "the metro most directly reveals his inability to use language for meaningful communication. [...] Johnny struggles to explain his thoughts, memories and feelings that transcend time. The metro experience facilitates this explanation" (2006: 382). Siguiendo de nuevo a Scholz, podemos afirmar que, en la obra de Cortázar, los transportes se convierten en lugares de máxima importancia. Concretamente, en El perseguidor el metro le sirve a Johnny para darse cuenta de la existencia de otro tipo de tiempo; esa vivencia se acaba trasladando a otros momentos de su vida, pero solo tiene consciencia plena de ello en el transporte (Scholz, 2000: 115-116). Además, el movimiento del medio de transporte posibilita una explosión espiritual en la interioridad del personaje: "el viaje [...] es una circunstancia totalmente exterior, o más exactamente el viaje horizontal, lineal con su itinerario clásico, con sus fases iniciáticas [...] no tiene tanta importancia como es de esperar. El viaje se reduce a un momento y punto fijos, determinados en los cuales algo sorprendente, inesperado sucede a la velocidad de un relámpago" (Scholz, 2000: 118-119). Así, el viaje es un modo de facilitar el extrañamiento o de abrirse a nuevas perspectivas, esto es, un método de conocimiento antirracional. El estudioso concluye que no se trata de un viaje vertical, sino de una búsqueda propiamente dicha, de una tentativa de conquistar la realidad en su plenitud (Scholz, 2000: 120-122).

Johnny va a intentar explicar esta búsqueda a Bruno —algo que, como ya sabemos, va a quedar truncado por la mediación del lenguaje - y, para ello, va a relatarle la experiencia que tiene en el metro. En un pequeñísimo lapso de tiempo, el minuto y medio que transcurre entre las estaciones de Odéon y Saint Germain-des-Prés, el protagonista reflexiona sobre su madre, su antiguo barrio, sobre Lan con su vestido verde... Unos pensamientos que habrían requerido unos quince minutos del tiempo cronológico. Además, el propio Johnny señala que estas reflexiones trascienden la categoría mental: "me parece que ya te he dicho muchas veces que yo no pienso nunca; estoy como parado en una esquina viendo pasar lo que pienso, pero no pienso lo que veo" (242). En el metro, como explica Reagan, Johnny "sees both what is in his mind and his memories as if they were really occurring simultaneously. Reality, the mortgage, religion, or the metro passengers do not cease to exist, but Johnny's perception of 
them becomes secondary and his memory, the past is juxtaposed with the present" (2006: 390-391). Ya hemos hablado de esa obsesión de Johnny por conseguir la simultaneidad temporal, pero lo que nos interesa especialmente es lo que apunta la estudiosa acerca de la yuxtaposición del pasado y el presente en este momento concreto, pues guarda una estrecha relación con la disposición formal del pasaje en la película de Wilenski.

Los momentos más destacables de la misma residen en la plasmación audiovisual del viaje en metro, una visualización de ese ascensor del tiempo. En estos, el montaje ${ }^{4}$ de la película recrea no solo el orden —o desorden - que Cortázar da a ese momento de lucidez de Johnny, sino que también sintetiza la concepción temporal de la novela corta. López Petzoldt señala que los rasgos de la narración de arte y ensayo presentan algunas equivalencias estéticas con la obra de Cortázar. Destaca las siguientes analogías entre sus prácticas narrativas y los modelos fílmicos: "la flexibilización o negación de las cadenas causales, la abierta ausencia de nexos lógicos entre los elementos de una historia, la negación de la firme dualidad entre lo presuntamente objetivo y subjetivo, así como también los procedimientos autorreflexivos-metanarrativos, entre otros" (López Petzold, 2014: 78). Asimismo, el estudioso destaca la potencialidad narrativa del montaje fílmico y propone una comparación de las técnicas narrativas de Cortázar con los tipos de montaje señalados por Amiel (López Petzold, 2014: 80-90); a continuación, procedemos a seguir este consejo para el caso particular de nuestro estudio.

Concretamente, la mentada escena del metro se articula a partir de lo que Amiel denomina "montaje de correspondencias" y que se caracteriza por una articulación discontinua de los planos, entre los que se establece una relación basada en los ecos formales. Además, el procedimiento estético dominante es el collage (Amiel, 2005: 26). A partir de ejemplos de diversas películas, Amiel señala lo que caracteriza a estos elementos:

las imágenes chocan entre sí, se golpean, se responden, sin ofrecer el límpido trayecto de una mirada que unifica. En su sucesión, los planos no elaboran una continuidad, [...] son fuentes evidentes de emoción sensible, de un caos en la percepción. [...] en su gran mayoría, no se refieren exactamente al mismo momento o a los mismos lugares [...]. Se trata de unas imágenes muy breves [...]. El montaje, practicado así como "collage" o como "pegado", sustituye todo tipo de necesidad por el azar y la sorpresa. (21-23)

Los ecos formales, que funcionan a modo de rimas visuales, normalmente se encuentran espaciados a lo largo de la película (Amiel, 2005: 127-129). En el caso que nos ocupa, el director va a acelerar el ritmo del montaje - y, en consecuencia, el narrativo- de una manera vertiginosa a través de la yuxtaposición de las imágenes. En esta escena, el montaje de correspondencias se ve sujeto, como la percepción de Johnny, a la elasticidad del tiempo subjetivo, presentando de manera contigua escenas que bien podrían estar repartidas en diversos momentos de la cinta: se trata, por lo tanto, de un recurso análogo a esa contraposición de pasado y presente que transcurre en la mente de Johnny. De hecho, el montaje de correspondencias también se caracteriza por un ensamblaje mediante asociaciones

\footnotetext{
${ }^{4}$ Según lo define Vincent Amiel, el concepto reúne las acepciones de dos términos en inglés: el cutting, o el ensamblaje físico o digital de los diferentes fragmentos de la película, y el editing, o planificación narrativa de la forma global del montaje. Sus diferentes tipos contribuyen a contar historias (montaje narrativo), a establecer relaciones de sentido (montaje discursivo), o a provocar emociones puntuales (montaje de correspondencias). Cada película muestra predominancia de uno de estos procedimientos, pero su estructura narrativa refleja varios de ellos (2005: 9-26).
} 
aleatorias que se transmiten de manera sugestiva; la imagen que se quiere dar del mundo, entonces, es la de algo que está por percibir (Amiel, 2005: 26). Efectivamente, las imágenes que vemos a través de la percepción de Juan parecen independientes las unas de las otras, pero en realidad se pueden establecer relaciones entre ellas a partir del paralelismo visual: la escena que nos interesa, más extensa que muchas otras de la película, comienza con Juan sentado en el metro y, repentinamente, advirtiendo a Marta al otro lado de una puerta acristalada. Esa visión hace que en la mente del protagonista se proyecte la imagen de un momento pasado, en el que se encontraba jugando en el parque con su niña, acompañado por la madre de esta. En el momento en el que observamos a Juan con su hija caminando en dirección a su madre, inmediatamente después le vemos a él de niño yendo hacia el mismo banco del parque en el que se encontraba esta, ahora de la mano de su hermana. También asistimos al viaje que el pequeño Juan realiza hacia el quiosco, donde compra una chocolatina, solo para después ver cómo su versión adulta ofrece una muy parecida a su novia (Wilenski, 1965: 00:34:55-00:37:50). La repetición de gestos, planos, cambios de luz, etc. que caracteriza al montaje de correspondencias y que podemos ver en la cinta del director argentino "ya no es solamente un disco rayado [...], sino la representación misma del mundo, que pierde así su sencillez lineal [...] [y] favorece una percepción no-cronológica" (Amiel, 2005: 134-135).

Para complicar aún más la situación, toda esa escena está inserta en un flashback: se encuadra en la conversación que Johnny mantiene con Bruno acerca de su viaje en el metro, es decir, en el momento equivalente al comienzo in medias res de la novela corta. Mientras Juan echa la cabeza hacia atrás, pensativo, oímos el sonido del metro antes de que este aparezca en escena - y, con él, la analepsis y el montaje de correspondencias que contiene-. El elemento auditivo complementa esta visualización de lo que Johnny únicamente relata en la novela corta: todas las escenas irán acompañadas por el sonido atenuado del subterráneo.

La opacidad que estas imágenes pueden ofrecer en un primer visionado - y que se vinculan con el carácter fragmentario de toda la película- se corresponde con otra de las peculiaridades del montaje de correspondencias: "la imagen no nos puede dar de inmediato todo su sentido [...]. El interés no está necesariamente en discernir las épocas y poderlas ubicar con nitidez; [...] [sino] en asociar, con años de distancia, ciertos sentimientos similares, ciertas percepciones de la duración o determinadas impresiones" (Amiel, 2005: 133-135). En definitiva, "la sucesión de las escenas es más importante que su contenido" (Amiel, 2005: 156). No se nos ocurre, por lo tanto, una manera de reflejar la obsesión de Johnny por la temporalidad: es un tema que le absorbe de manera completa, que le lleva a considerar su estabilidad familiar como "trampas", "porque no puede ser que no haya otra cosa, no puede ser que estemos tan cerca, tan del otro lado de la puerta" (277). La búsqueda del saxofonista, como el repentino visionado de varios momentos de su vida en la película, va a adquirir más relevancia que su propia vida.

\section{Conclusiones}

A modo de síntesis, podemos afirmar que el tratamiento de la temporalidad y su unión al motivo del viaje en metro es el factor que reúne las visiones artísticas de Cortázar y Wilenski. Las modificaciones que este introduce en su película - la mayor linealidad de los sucesos y el 
desplazamiento del narrador en primera persona - resultan significativas a la hora de analizar el conflicto de los protagonistas: los perseguidores quedan reducidos a la mitad y la búsqueda de Johnny pierde gran parte de su calado metafísico. Sin embargo, su película busca la renovación formal, común al resto de integrantes de la Generación del 60, y en ella está el mayor rasgo de modernidad. El texto cortazariano establece las coordenadas espaciotemporales como un eje fluctuante. Así, el protagonista logra percibir, aunque sea de manera momentánea, la temporalidad como un continuum que la experiencia lógica va a fragmentar y, como consecuencia, nos impide acceder a su comprensión subjetiva. La consecución de esta experiencia, por lo tanto, se cifra en una apertura hacia la suprarrealidad, algo que también buscan los protagonistas de Rayuela o Los premios. El acceso a este otro lado no va a ser posible a través del lenguaje, por lo que Johnny debe recurrir a otro medio artístico, el jazz. Su exploración también es posible, aunque de manera involuntaria, a través de los viajes en metro. Así, se unen en esta escena la simultaneización temporal del relato de Cortázar - la vida pasada de Johnny y la presente, en ese tiempo subjetivo y dilatado- con la representación formal del montaje de correspondencias de Wilenski.

\section{Bibliografía}

AGUILAR, Gonzalo (2005): "La Generación del 60. La gran transformación del modelo". En Claudio España (dir.), Cine argentino: modernidad y vanguardias (1957/1983) II. Buenos Aires, Fondo Nacional de las Artes: 82-97.

AMIEL, Vincent (2005): Estética del montaje. Trads. Monique Perriaux y Vicente Carmona. Madrid, Abada.

ANCHOU, Gregorio (2005): "La pequeña ola. Colgada de la Generación del 60, una vasta pasión creadora". En Claudio España (dir.), Cine argentino: modernidad y vanguardias (1957/1983) II. Buenos Aires, Fondo Nacional de las Artes: 194-207.

ARIAS CAREAGA, Raquel (2014): Julio Cortázar. De la subversión literaria al compromiso político. Madrid, Sílex.

ARONNE-AMESTOY, Lida (1983): "La búsqueda del «yo» al «nosotros». Génesis y definición del tema del perseguidor en Julio Cortázar". En Jaime Alazraki, Ivar Ivask y Joaquín Marco (eds.), La isla final: Julio Cortázar. Madrid, Ultramar: 373-389.

AQUILANTI, Lucio y Federico BAREA (2014): Todo Cortázar. Bio-bibliografía. Segunda impresión corregida y aumentada. Buenos Aires, Fernández Blanco.

BORELlO, Rodolfo (1980): “Charlie Parker: «El Perseguidor»”. Cuadernos Hispanoamericanos 364-366 (1980), 573-594.

CORTÁZAR, Julio (2000a): Cartas. 1937-1963 I. Edición a cargo de Aurora Bernárdez. Buenos Aires, Alfaguara.

--- (2000b): Cartas. 1964-1968 II. Edición a cargo de Aurora Bernárdez. Buenos Aires, Alfaguara.

--- (2015): “El perseguidor”. Cuentos completos I (1945-1966). Madrid, Alfaguara: 235-280.

FELDMAN, Simón (1990): La generación del 60. Buenos Aires, Instituto Nacional de Cinematografía / Editorial Legasa / Ediciones Culturales Argentinas. 
FÉLIX-DIDIER, Paula (2003): “Introducción”. En Fernando Martín Peña (ed.), 60 generaciones; 90 generaciones: cine argentino independiente. Buenos Aires, Fundación Eduardo F. Constantini: 11-20.

FILER, Malva E. (1972): “La búsqueda de autenticidad”. En Helmy F. Giacoman (ed.), Homenaje a Julio Cortázar. Variaciones interpretativas en torno a su obra. Nueva York, Las Américas: 195-206.

GARCÍA, Graciela: “Time, Language, Desire: Julio Cortázar's The Pursuer". Pacific Coast Philology 38 (2008): 33-39.

GOLOBOFF, Mario (1998): Julio Cortázar, la biografia. Buenos Aires, Seix Barral.

HARSS, Luis (1966): Los nuestros. Buenos Aires, Sudamericana.

LÓPEZ PETZOLDT, Bruno (2014): Los relatos de Julio Cortázar en el cine de ficción (1962-2009). Madrid, Iberoamericana. DOI: https://doi.org/10.31819/9783954878000

LUKA, Ezequiel (2003): “El perseguidor”. En Fernando Martín Peña (ed.), 60 generaciones; 90 generaciones: cine argentino independiente. Buenos Aires, Fundación Eduardo F. Constantini: 285-286.

MAHIEU, José Agustín (1980): “Cortázar en cine”. Cuadernos Hispanoamericanos 364-366 (1980): 640-646.

MANRUPE, Raúl y María Alejandra PORTELA (2001): Un diccionario de films argentinos (1930-1995). Buenos Aires, Corregidor.

MARTÍN PEÑA, Fernando (ed.) (2003): 60 generaciones; 90 generaciones: cine argentino independiente. Buenos Aires, Fundación Eduardo F. Constantini.

MARTÍNEZ, Adolfo C. (2004): Diccionario de directores del cine argentino (de comienzos del sonoro a nuestros días). Buenos Aires, Corregidor.

NEIFERT, Agustín (2003): Del papel al celuloide. Escritores argentinos en el cine. Buenos Aires, La Crujía.

REAGAN, Patricia (2006): "Going Under: The Metro and the Search of Oneself in Julio Cortázar's The Pursuer". Studies in 20th \& 21st Century Literature 30 (2) (2006): 380-397. DOI: https://doi.org/10.4148/2334-4415.1638

SCHOLZ, László (2000): Ensayos sobre la modernidad literaria hispanoamericana. Murcia, Servicio de Publicaciones.

SOSNOWSKI, Saúl (1973): Julio Cortázar, una búsqueda mítica. Buenos Aires, Ediciones Noé.

WILENSKI, Osías, dir. (1965): El perseguidor [cinta cinematográfica]. Argentina, Producciones Wilenski.

(C) Laura Ros Cases

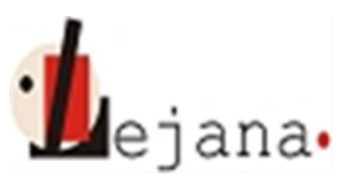

http://ojs.elte.hu/index.php/lejana

Universidad Eötvös Loránd, Departamento de Español, 1088 Budapest, Múzeum krt. 4/C 